Antibacterial and Antibiofilm Formation Activities of Pyridinium-based Cationic Pillar[5]arene Against Pseudomonas aeruginosa

Hua Yang ${ }^{\dagger}$, Leqiong Jinł, Dengqi Zhao ${ }^{\dagger}$, Zhifeng Lian ${ }^{\dagger}$, Appu Manikandan ${ }^{\dagger}$, Jianying Huang ${ }^{\dagger}{ }^{*}$ Zibin Zhang, ${ }^{\ddagger}$

†College of Food Science and Biotechnology, Zhejiang Gongshang University, Hangzhou 310018, P. R. China

${ }^{\ddagger}$ College of Material, Chemistry and Chemical Engineering, Hangzhou Normal University, Hangzhou 310036, P. R. China

*Corresponding authors: Tel: 86-571-2887-7777, E-mail: huangjy@zjgsu.edu.cn

*Corresponding authors: Tel: 86-571-2886-8023, E-mail: zzhang@hznu.edu.cn 
${ }^{1} \mathrm{H}$ and ${ }^{13} \mathrm{C}$ NMR spectra were measured on a $500 \mathrm{MHz}$ Bruker Avance NMR spectrometers (Bruker, Germany) at $25{ }^{\circ} \mathrm{C}$. Chemical shifts $(\delta)$ are given in part per million (ppm) and spin-spin coupling $(J)$ in Hz. High-resolution electrospray mass spectra were recorded on a A\&B 4000 Q TRAP instrument (A\&B, USA).

Synthesis and characterization of the two cationic pillar[5]arenes 


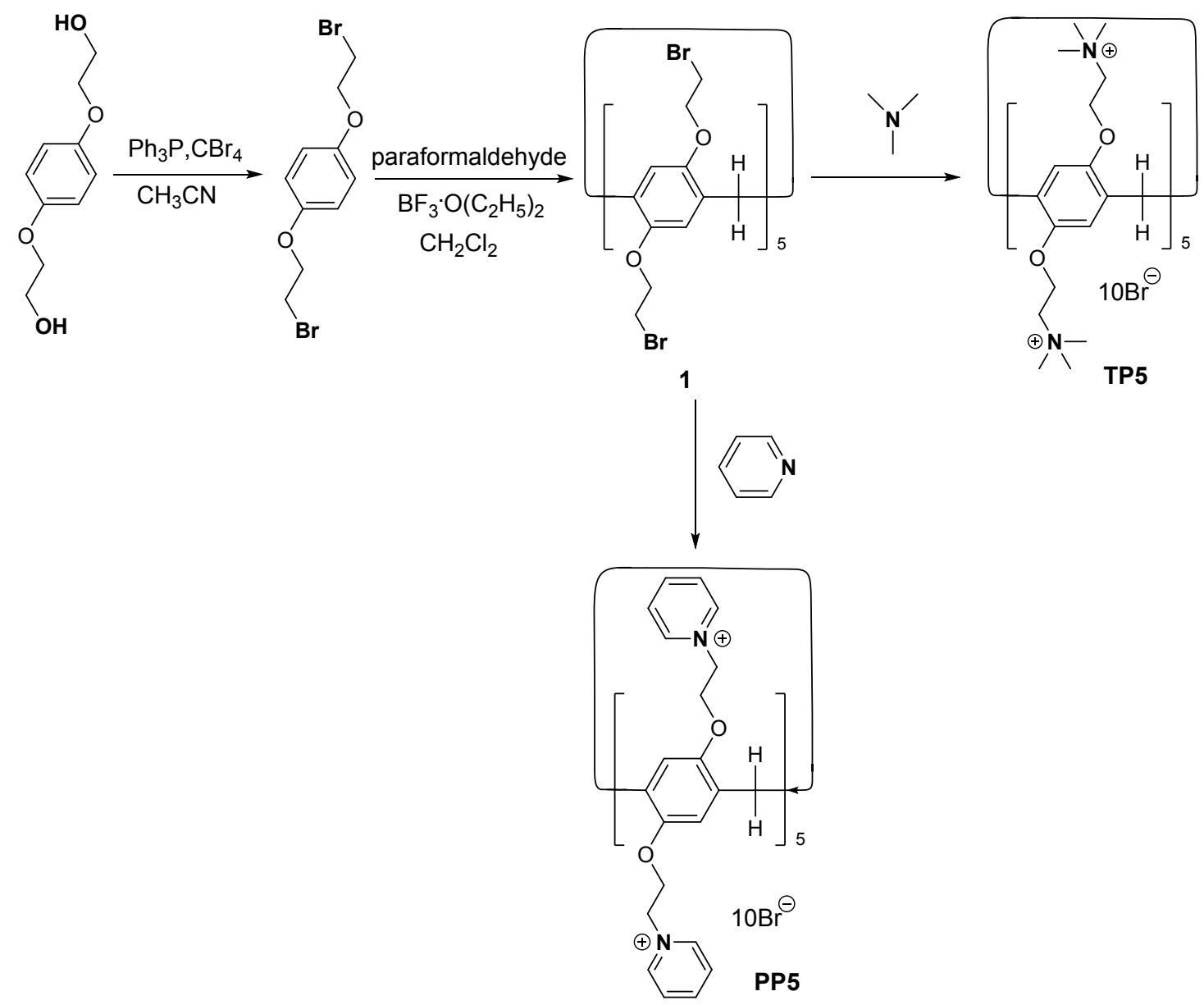

Scheme 1. Synthesis of two cationic pillar[5]arenes based on trimethylamine (TP5) and pyridine (PP5) .

\section{Synthesis of 1,4-bis(2-bromoethoxy)benzene ${ }^{1,2}$}

Carbon tetrabromide (39.8 g $120 \mathrm{mmol})$ was added slowly to a mixture of 2-[4-(2hydroxyethoxy)phenoxy]ethanol (9.91 g, $50 \mathrm{mmol})$, triphenylphosphine (31.5 g, 120 mmol) and acetonitrile $(250 \mathrm{~mL})$ at $0{ }^{\circ} \mathrm{C}$. After the solid was dissolved completely, it was stirred at room temperature for $4 \mathrm{~h}$. The reaction solution was poured into cold water $(500 \mathrm{~mL})$. Then the white precipitate was collected by suction filtration, and rinsed with $100 \mathrm{~mL}$ methanol/water (60/40). The crude product was recrystallized from methanol to obtain 1,4-bis(2-bromoethoxy)benzene as a white solid (10.36 g, $64.3 \%$ ). 
${ }^{1} \mathrm{H}$ NMR $\left(500 \mathrm{MHz}, \mathrm{CDCl}_{3}\right) \delta 6.86(\mathrm{~s}, 4 \mathrm{H}), 4.24(\mathrm{t}, J=6.3 \mathrm{~Hz}, 4 \mathrm{H}), 3.61(\mathrm{t}, J=6.3 \mathrm{~Hz}$, $4 \mathrm{H})$.

\section{Synthesis of $1^{1,2}$}

A mixture of 1,4-bis(2-bromoethoxy)benzene (3.24 g, $10 \mathrm{mmol})$, paraformaldehyde $(0.57 \mathrm{~g}, 19 \mathrm{mmol})$ and $1,2-$ dichloroethane $(130 \mathrm{~mL})$ was added to a $250 \mathrm{~mL}$ roundbottom flask. Then boron trifluoride ethyl ether complex $(2.4 \mathrm{~mL}, 19 \mathrm{mmol})$ was injected by a syringe. After stirred at room temperature for 10-30 min, it was quenched by water. The organic layer was dried over anhydrous $\mathrm{Na}_{2} \mathrm{SO}_{4}$ and evaporated to afford the crude product, which was isolated by flash column chromatography with DCM: $\mathrm{PE}=1: 2$ to obtain 1 as a white solid $(1.04 \mathrm{~g}, 30.4 \%) .{ }^{1} \mathrm{H}$ NMR $(500 \mathrm{MHz}$, $\left.\mathrm{CDCl}_{3}\right) \delta 6.91(\mathrm{~s}, 10 \mathrm{H}), 4.23(\mathrm{t}, J=5.6 \mathrm{~Hz}, 20 \mathrm{H}), 3.84(\mathrm{~s}, 10 \mathrm{H}), 3.63(\mathrm{t}, J=5.6 \mathrm{~Hz}$, $20 \mathrm{H})$.

\section{Synthesis of $\mathbf{T P 5} 5^{1,2}$}

A mixture of $1(0.168 \mathrm{~g}, 0.1 \mathrm{mmol})$, a methanol solution of trimethylamine $(4 \mathrm{~mL}$, $13 \mathrm{mmol})$ and absolute ethanol $(100 \mathrm{~mL})$ was refluxed at $90{ }^{\circ} \mathrm{C}$ for $24 \mathrm{~h}$. After the solvent was removed under reduced pressure, TP5 was obtained as a white solid $(0.177$ g, $78.1 \%) .{ }^{1} \mathrm{H}$ NMR (500 MHz, D $\left.2 \mathrm{O}\right) \delta 6.92(\mathrm{~s}, 10 \mathrm{H}), 4.42(\mathrm{~s}, 20 \mathrm{H}), 3.90$ (s, 10H), 3.77 (s, 20H), 3.19 (s, 90H). ESI-MS: $m / z=1055.7550$ for $[\mathrm{M}-2 \mathrm{Br}]^{2+}$.

\section{Synthesis of PP5}

Compound 1 (0.168 g, $0.1 \mathrm{mmol})$ was refluxed in $20 \mathrm{~mL}$ pyridine for $48 \mathrm{~h}$. After the 
solution was cooled down to room temperature, PP5 was precipitated as a yellow solid. It $(0.237 \mathrm{~g}, 96 \%)$ was collected by filtration and washed several times with dichloromethane. ${ }^{1} \mathrm{H}$ NMR $\left(500 \mathrm{MHz}, \mathrm{D}_{2} \mathrm{O}\right) \delta 8.71(\mathrm{~d}, J=5.8 \mathrm{~Hz}, 20 \mathrm{H}), 8.30(\mathrm{t}, J=$ $7.8 \mathrm{~Hz}, 10 \mathrm{H}), 7.98-7.81(\mathrm{~m}, 20 \mathrm{H}), 6.53(\mathrm{~s}, 10 \mathrm{H}), 4.97-4.86(\mathrm{~m}, 20 \mathrm{H}), 4.51-4.39(\mathrm{~m}$, 20H), 3.40 (s, 10H). ${ }^{13} \mathrm{C}$ NMR (125 MHz, $\left.\mathrm{D}_{2} \mathrm{O}\right) \delta 149.0(\mathrm{~s}), 146.08(\mathrm{~s}), 144.61(\mathrm{~s})$, 129.93 (s), 128.05 (s), 115.73 (s), 67.11 (s), 60.78 (s), 30.21 (s), 29.20 (s). ESI-MS: $m / z=1155.5816$ for $[\mathrm{M}-2 \mathrm{Br}]^{2+}$.

\section{${ }^{1} \mathrm{H}$ and ${ }^{13} \mathrm{C}$ NMR and High-resolution mass spectroscopy}

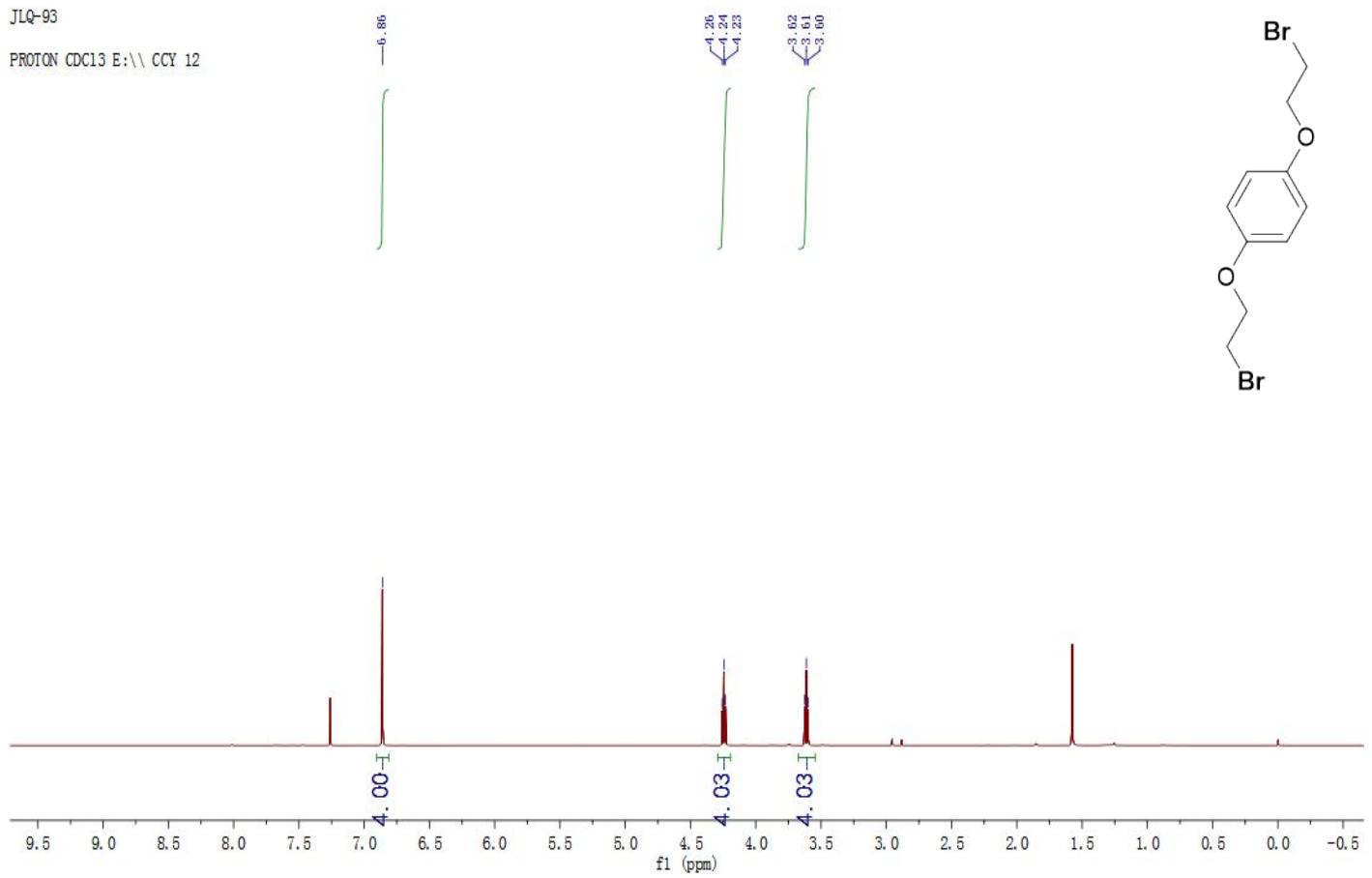

Figure S1. ${ }^{1} \mathrm{H}$ NMR of compound 1 in $\mathrm{CDCl}_{3}$ at $25^{\circ} \mathrm{C}$. 
Figure S1. ${ }^{1} \mathrm{H}$ NMR of spectrum $\left(500 \mathrm{MHz}\right.$, chloroform-d, $\left.25{ }^{\circ} \mathrm{C}\right)$ of 1,4-bis(2bromoethoxy)benzene.

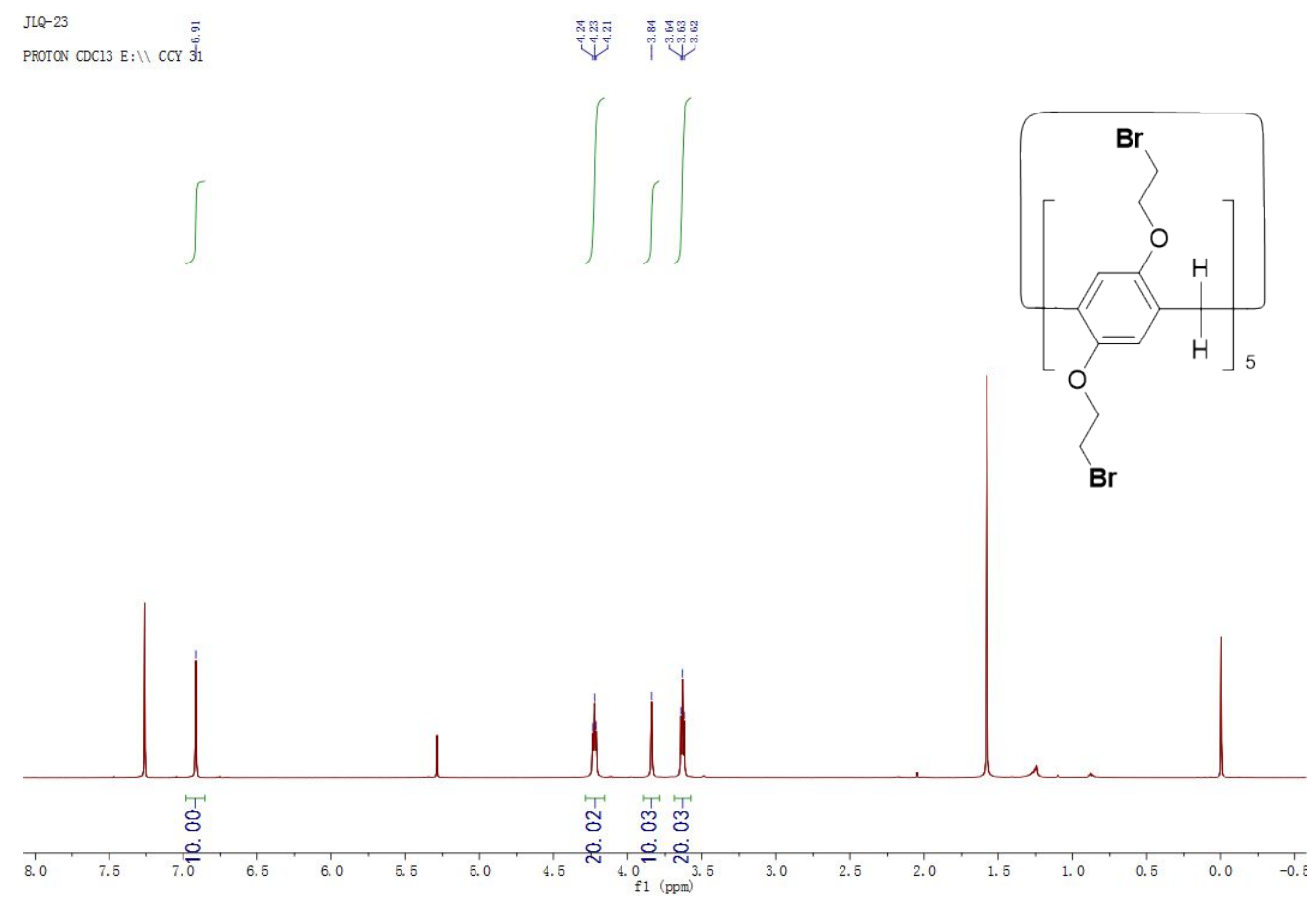

Figure S2. ${ }^{1} \mathrm{H}$ NMR of spectrum $\left(500 \mathrm{MHz}\right.$, chloroform- $\left.d, 25^{\circ} \mathrm{C}\right)$ of 1 . 


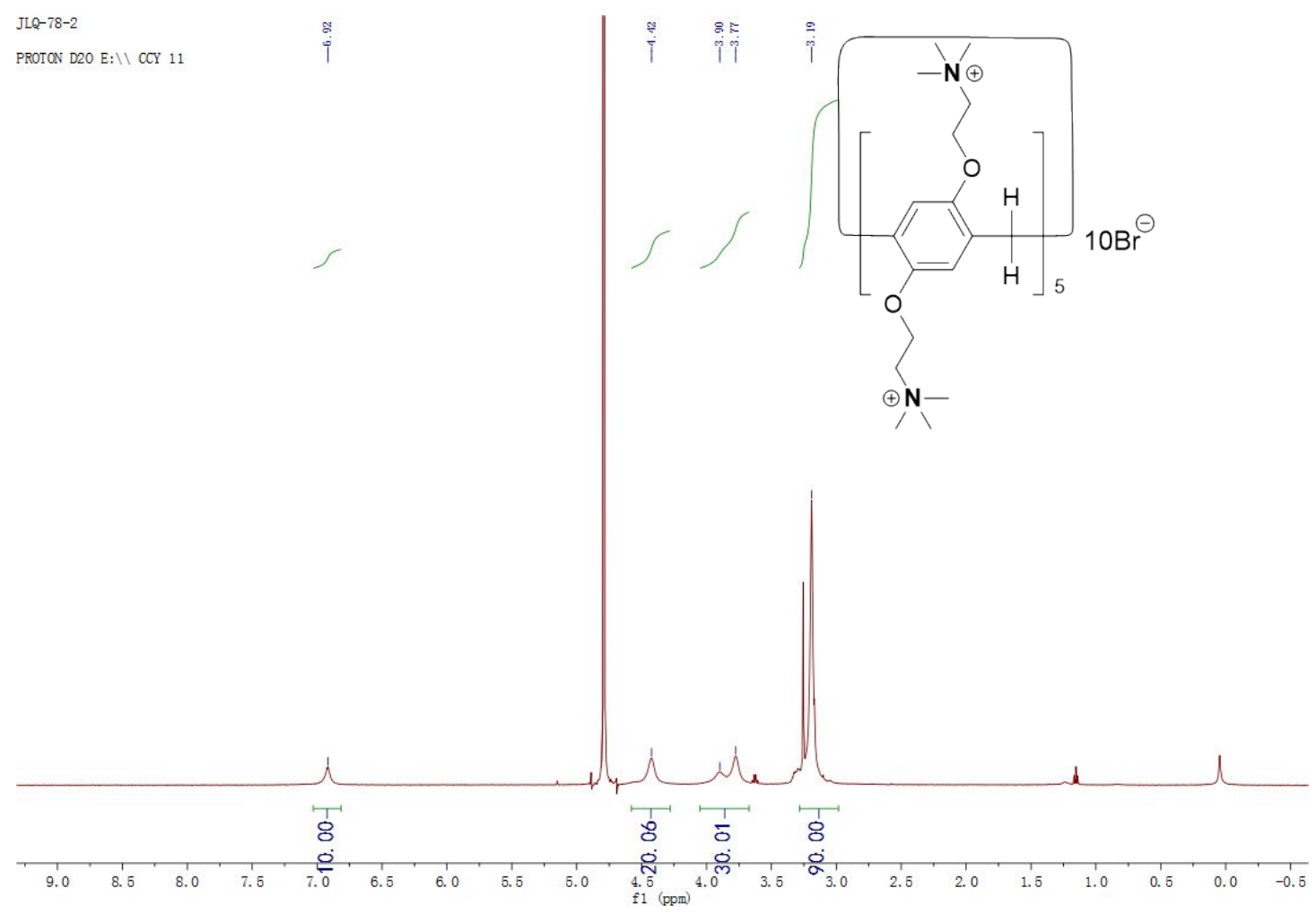

Figure S3. ${ }^{1} \mathrm{H}$ NMR of spectrum $\left(500 \mathrm{MHz}, \mathrm{D}_{2} \mathrm{O}, 25^{\circ} \mathrm{C}\right)$ of TP5.

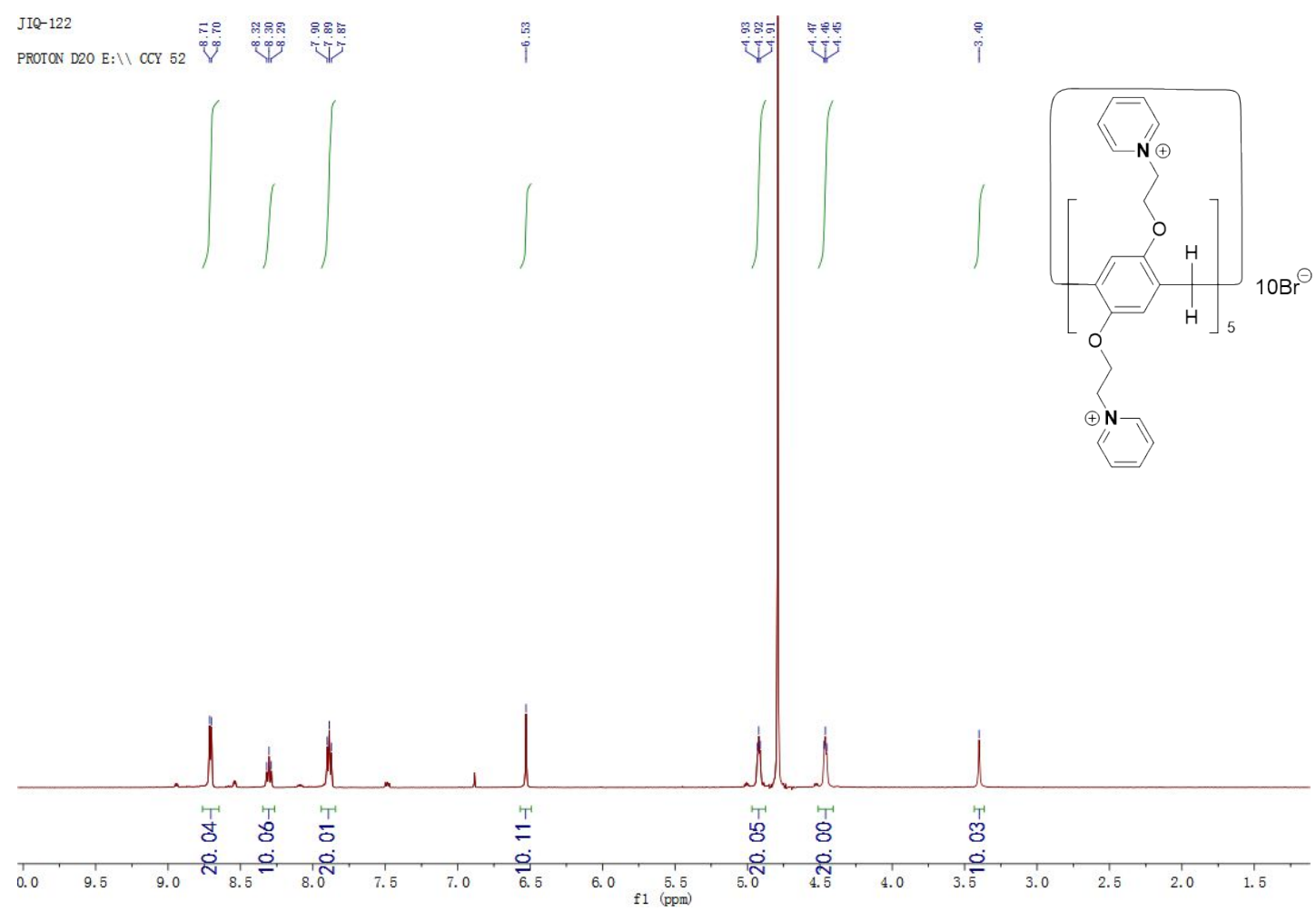

Figure S4. ${ }^{1} \mathrm{H}$ NMR of spectrum $\left(500 \mathrm{MHz}, \mathrm{D}_{2} \mathrm{O}, 25^{\circ} \mathrm{C}\right)$ of $\mathrm{PP} 5$. 


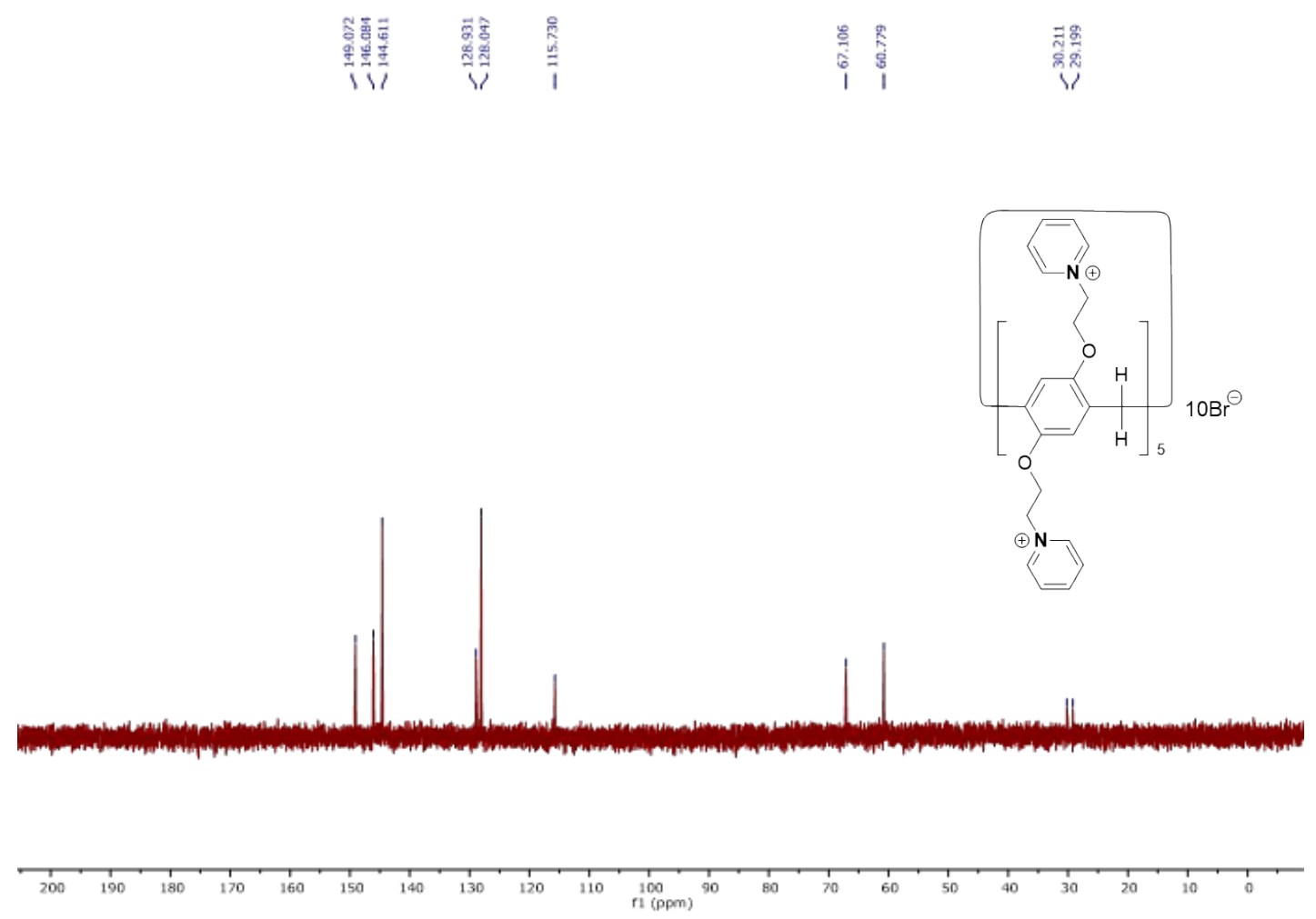

Figure S5. ${ }^{13} \mathrm{C}$ NMR of spectrum $\left(125 \mathrm{MHz}, \mathrm{D}_{2} \mathrm{O}, 25{ }^{\circ} \mathrm{C}\right)$ of PP5.

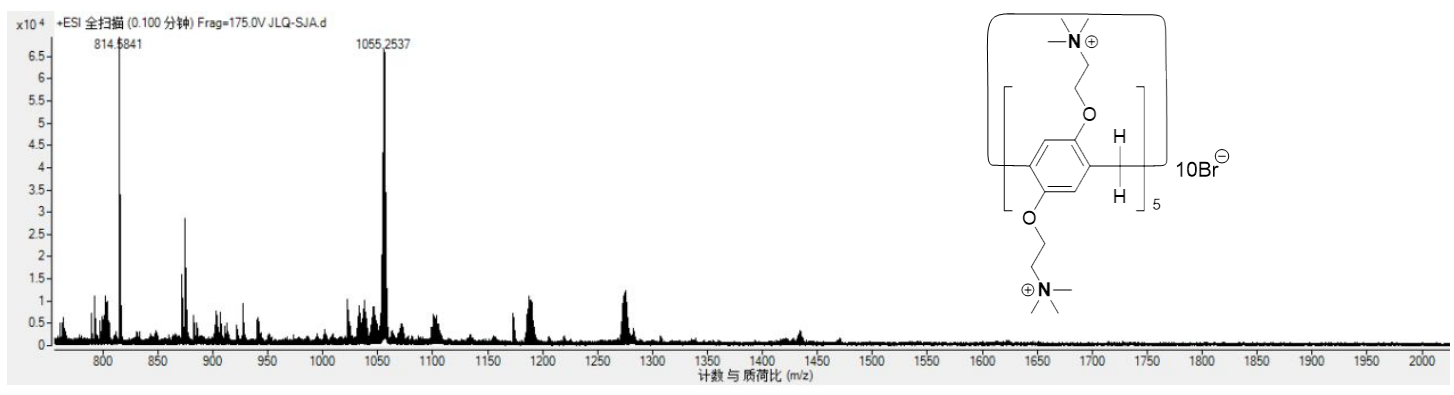



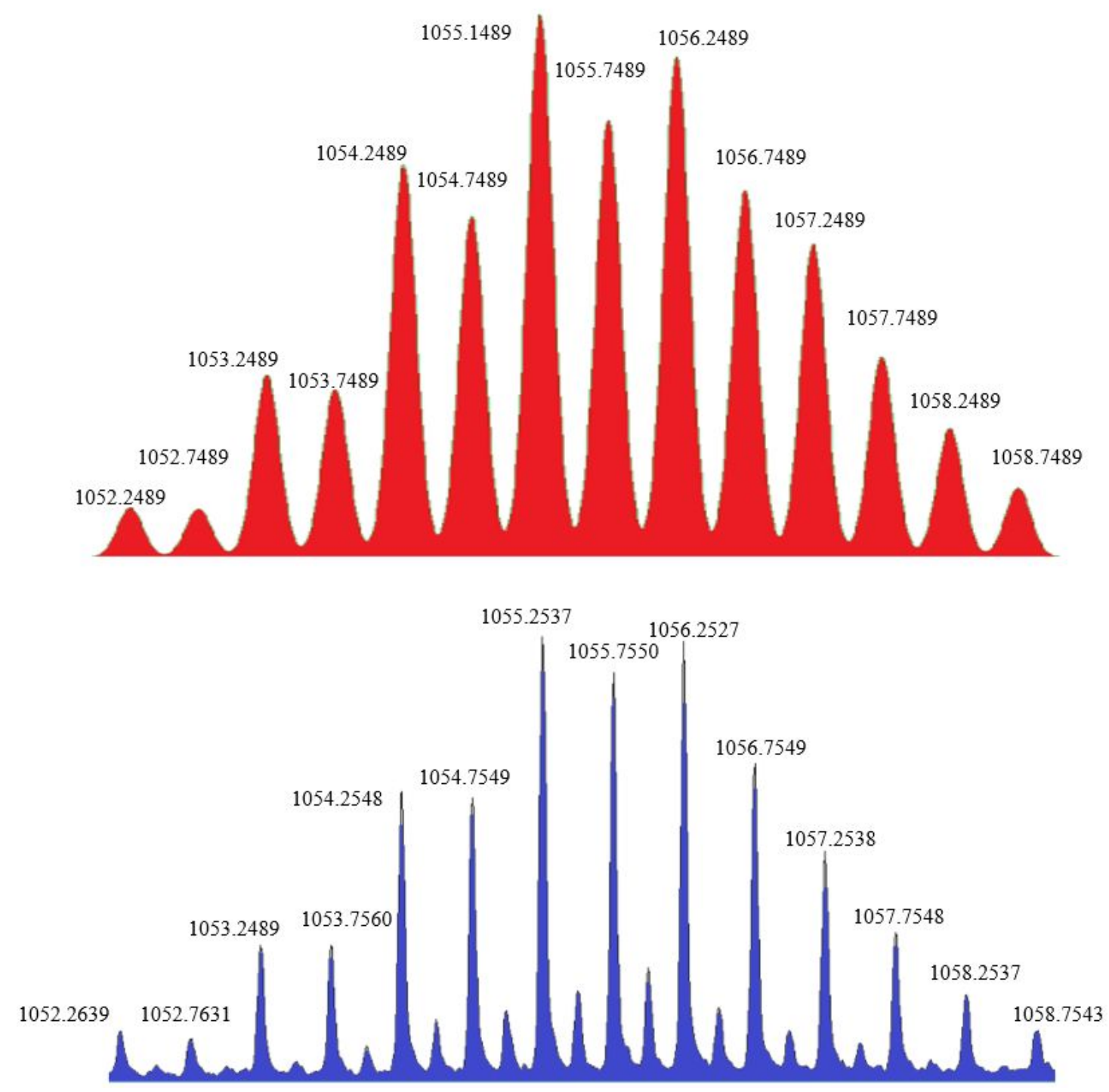

Figure S6. ESI mass spectrum of TP5, $[\mathrm{M}-2 \mathrm{Br}]^{2+}$ at $m / z=1055.7550$ (blue) and its simulated spectrum (red).

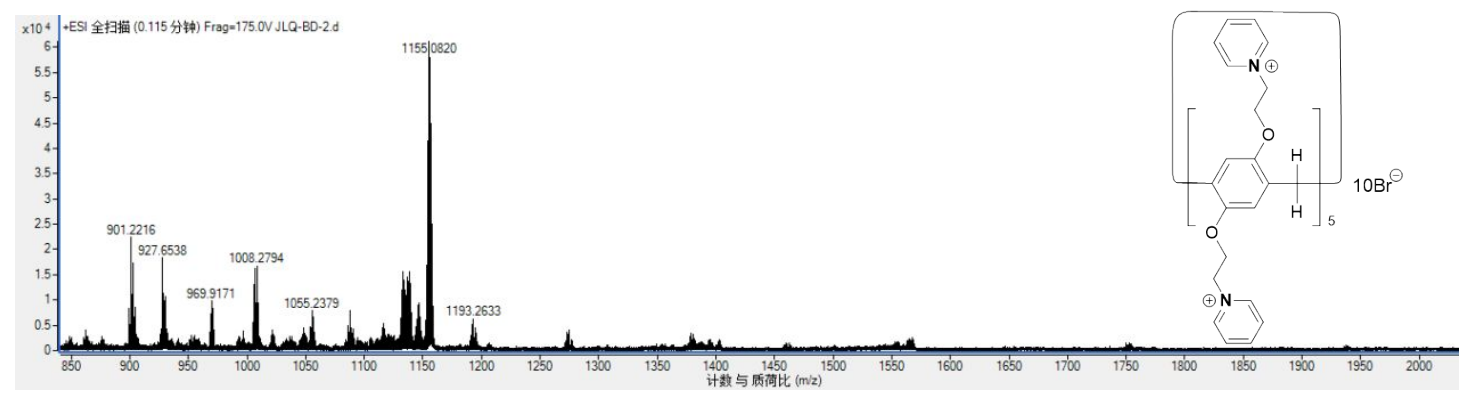



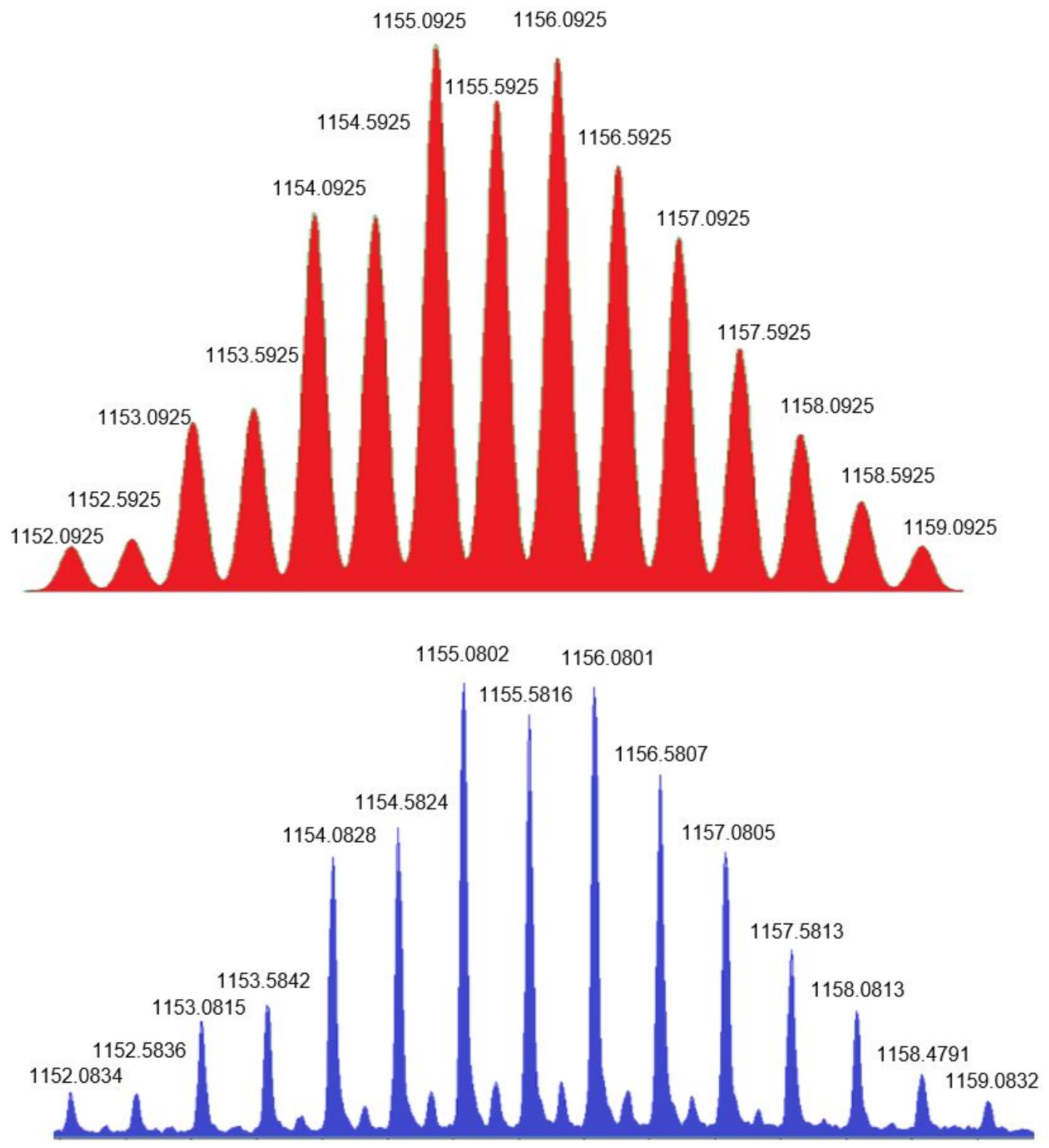

Figure S7. ESI mass spectrum of $\mathrm{PP} 5,[\mathrm{M}-2 \mathrm{Br}]^{2+}$ at $\mathrm{m} / \mathrm{z}=1155.5816$ (blue) and its simulated spectrum (red). 


\section{MIC and MBC of TP5 against $P$. aeruginosa PAO1}
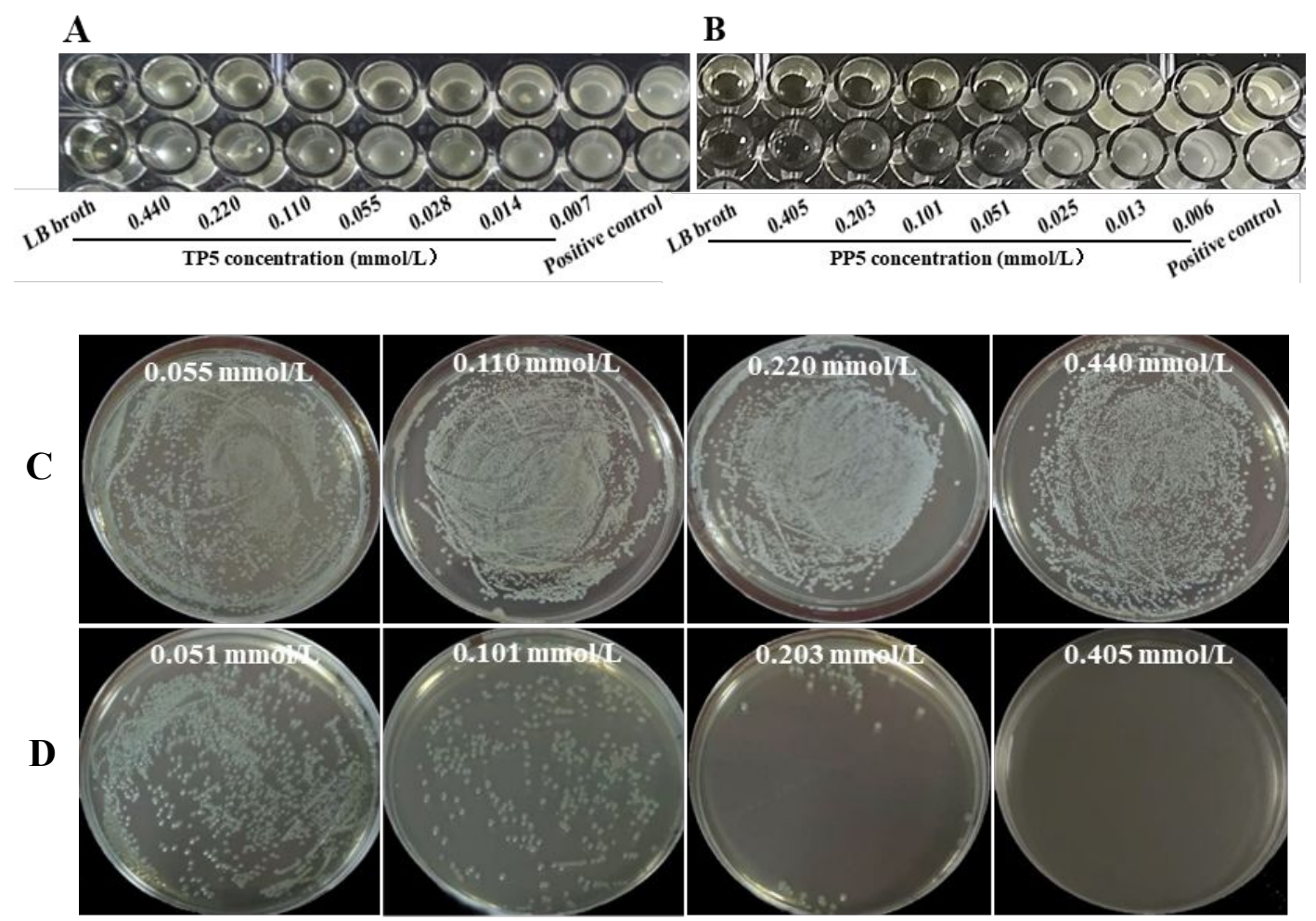

Figure S8. The MICs of TP5 and PP5 against $P$. aeruginosa PAO1 (A, B); MBC images of $P$. aeruginosa PAO1, colonies treated with TP5 (C) and PP5 (D) on the TSA agar plates. All cells were subjected for $24 \mathrm{~h}$ of incubation on TSA agar plates at $37^{\circ} \mathrm{C}$.

\section{Antibacterial activities}

In short, bacterial cells were cultured overnight (approx. $10^{7} \mathrm{CFU} / \mathrm{mL}$ ) in a liquid medium containing Luria-Bertani $+1 \%$ Glucose and centrifuged (5000 rpm for $3 \mathrm{~min}$ ). The supernatant was removed and washed twice with PBS (PBS, $\mathrm{pH}=7.2-7.4)$. The prepared antibacterial agent $(1 \mathrm{~mL})$ was added into the washed bacterial solution, which was further shaken at $37^{\circ} \mathrm{C}$ for $24 \mathrm{~h}$. The suspension was diluted appropriately. Then the diluted suspension $(100 \mu \mathrm{L})$ was flattened on a solid TSA plate and incubated at 37 ${ }^{\circ} \mathrm{C}$ for $24 \mathrm{~h}$. Finally, the viability of bacteria was determined according to the number 
of colony forming units.

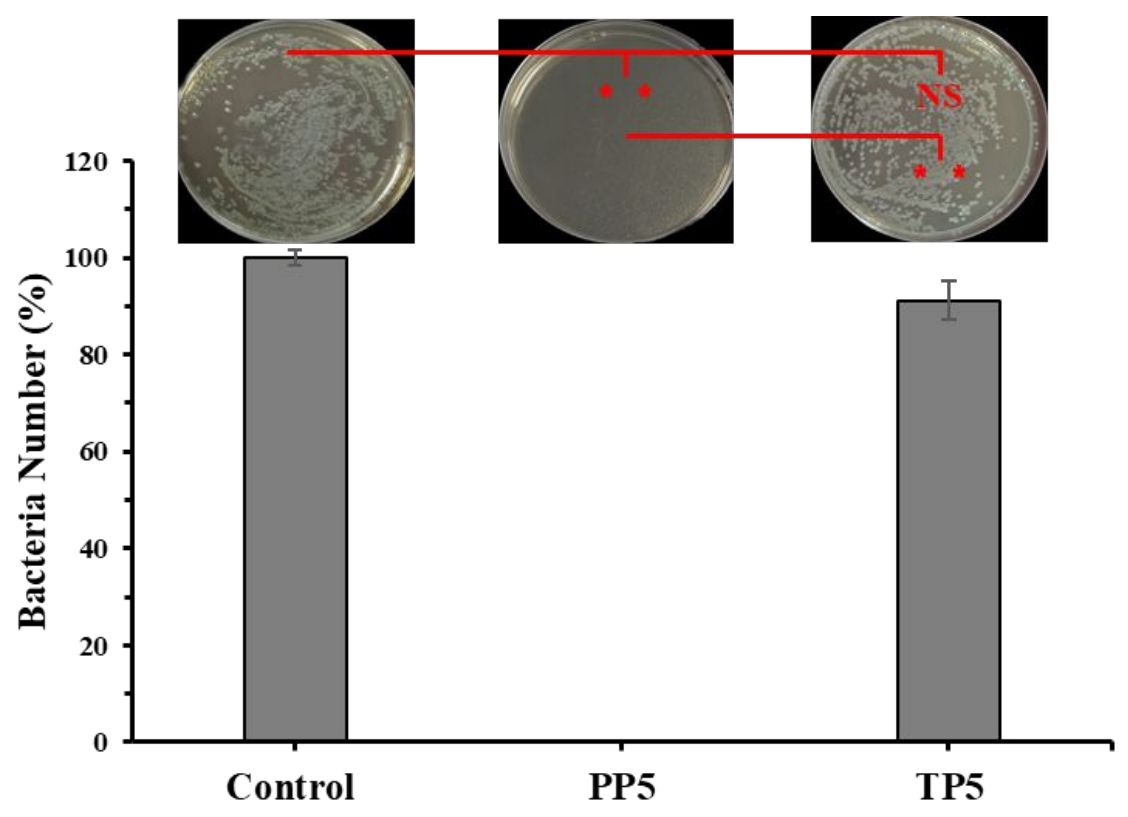

Figure S9. Images of $P$. aeruginosa PAO1 colonies treated with PP5 $(0.405 \mathrm{mmol} / \mathrm{L})$ and TP5

$(0.440 \mathrm{mmol} / \mathrm{L})$ on the TSA agar plates, respectively; And, relative bacterial numbers of $P$. aeruginosa PAO1 $\left({ }^{*} p<0.05,{ }^{* *} p<0.01\right)$. All cells were subjected to $24 \mathrm{~h}$ of incubation at $37{ }^{\circ} \mathrm{C}$.

\section{Antibiofilm formation assay}

Briefly, $1 \%$ of overnight cultures of the tested strains was added into fresh LuriaBertani supplemented with $1 \%$ Glucose. After being diluted by growth medium to $5 \times 10^{5} \mathrm{CFU} / \mathrm{mL}, 100 \mu \mathrm{L}$ of bacteria was dispensed into each well of 96-well polystyrene flat-bottomed microtiter plates respectively, in the presence of $100 \mu \mathrm{L}$ of test compounds and then incubated without agitation for $24 \mathrm{~h}$ at $37^{\circ} \mathrm{C}$.

Crystal-violet (CV) biofilm assay ${ }^{3}$. After incubation, the wells were washed with PBS to remove planktonic bacteria. The remaining bacteria were subsequently stained 
with $0.4 \%$ crystal violet solution for $15 \mathrm{~min}$ at room temperature. Wells were washed once again to remove the crystal violet solution and non-specifically stained adherent bacteria. Microplates were inverted and gently tap on paper towels to remove any excess liquid and then air dried. $200 \mu \mathrm{L}$ of $95 \%$ ethanol were filled into the plates. Finally, the optical density of each well was measured at a wavelength of $600 \mathrm{~nm}$. Each concentration of compound was tested in three replicates, and three independent experiments were performed.
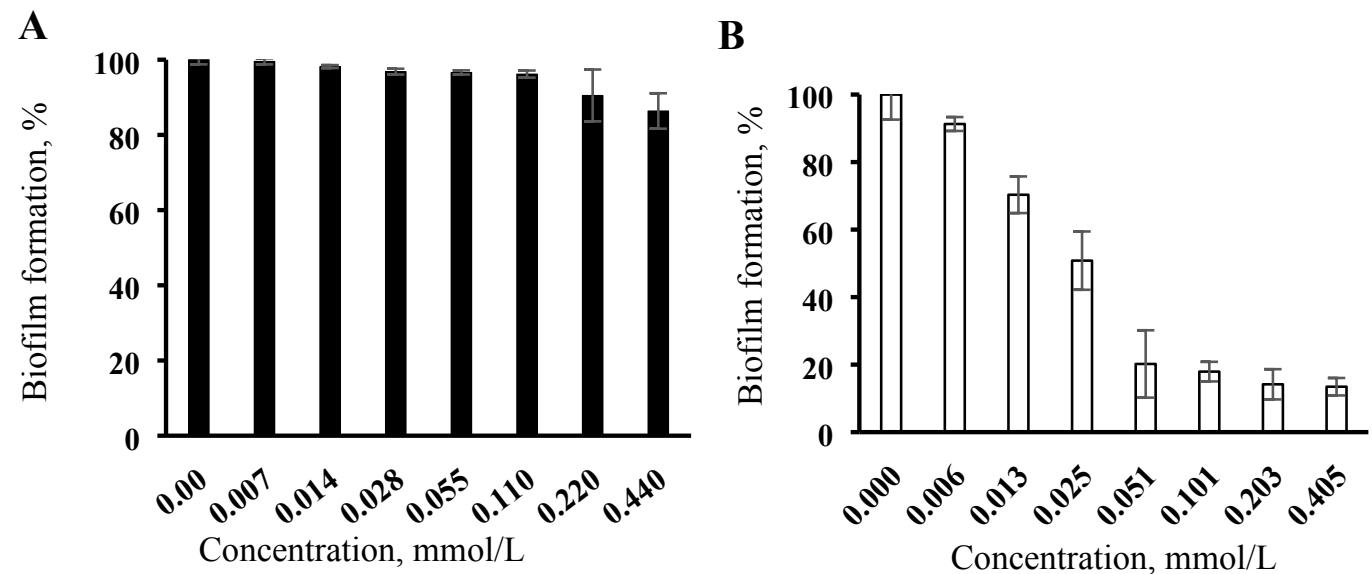

Figure S10. Effects of TP5 (A) and PP5 (B) compounds on biofilm formation of P. aeruginosa PAO1. All cells were subjected for $24 \mathrm{~h}$ of incubation on TSA agar plates at $37^{\circ} \mathrm{C}$. 


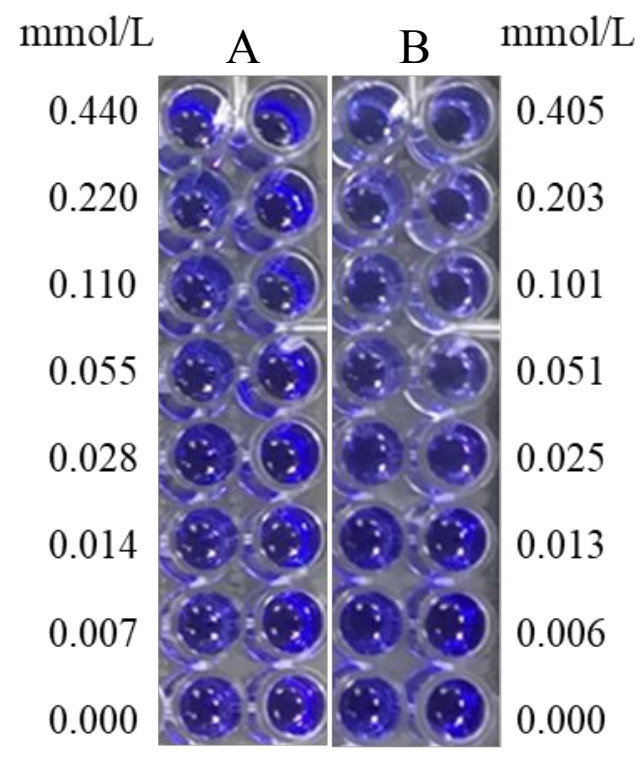

Figure S11. Biofilms formed by $P$. aeruginosa $\mathrm{PAO} 1$ in the presence of increasing concentrations of pillar[5]arene derivatives (A) TP5 and (B) PP5 stained with CV. The visible color change from deep to shallow showed the inhibition of biofilms (from bottom to top).

Effects of MIC and Sub-MIC PP5 to P. aeruginosa PAO1 Adhesion. ${ }^{4}$ The bacteria adhesion assay was performed using the spread plate method. After general incubation $\left(37^{\circ} \mathrm{C}, 24 \mathrm{~h}\right)$. The cover slides cultured in a $24-$ well plate were taken out with sterile tweezers and rinsed gently with sterile PBS (to remove planktonic bacteria). The rinsed cover slides were placed in a centrifuge tube containing $2 \mathrm{~mL}$ normal saline. After ultrasonic for $5 \mathrm{~min}$ at $150 \mathrm{~W}$ power, the lid slides were oscillated with a vortex oscillator and continuously diluted with $100 \mathrm{uL}$ continuous gradient dilution. Then, the coating is carried out on the solid TSA plate. 


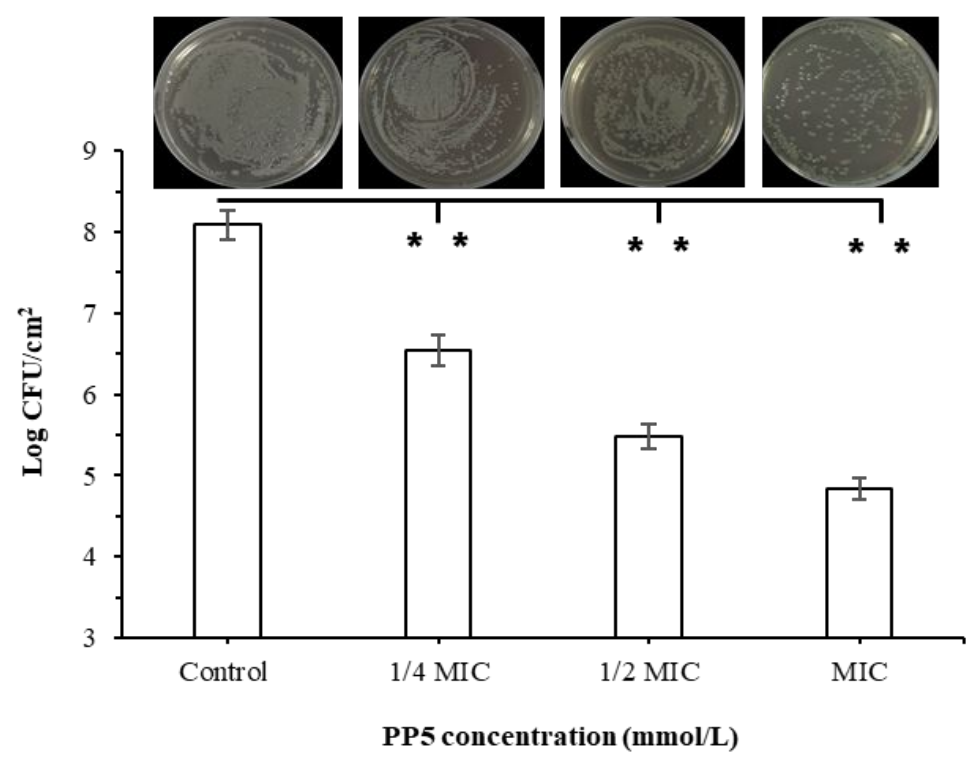

Figure S12. The number of viable bacteria ( $P$. aeruginosa PAO1) from PP5 treated biofilm on coverslip surfaces. The error bars represent the standard deviation of experiments performed in triplicate $(\mathrm{n}=3)$.

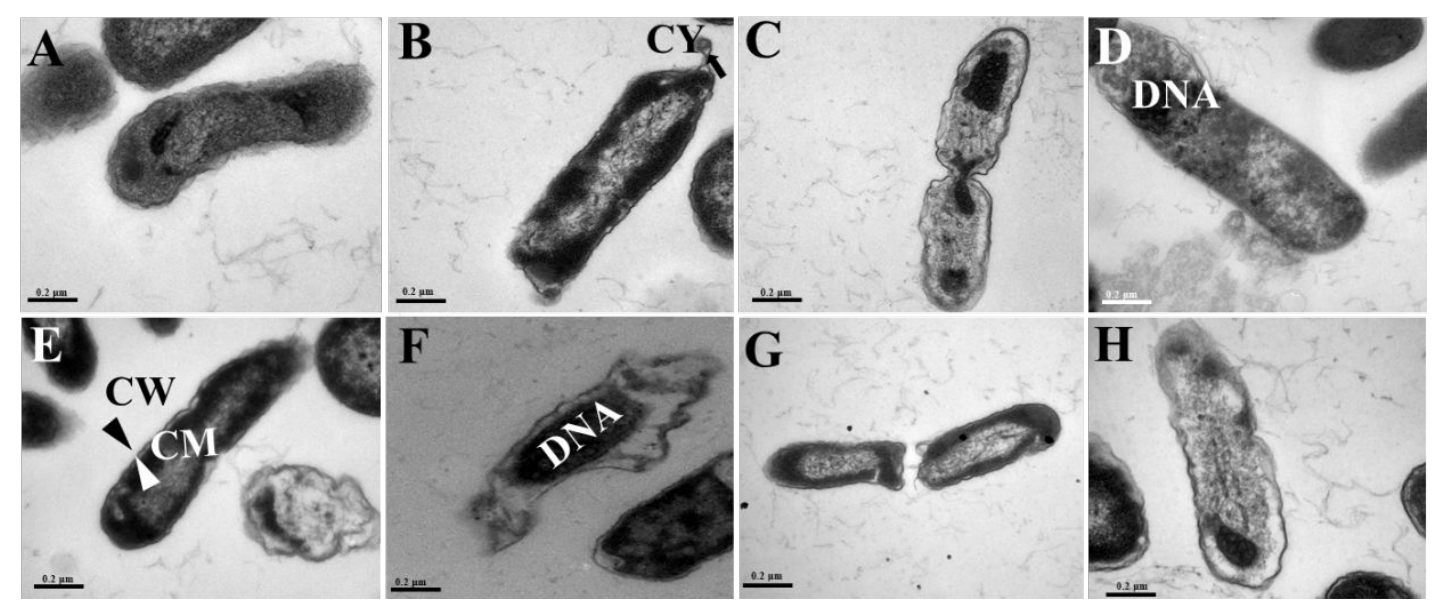


Figure S13. Effect on the cell morphology of $P$. aeruginosa PAO1: PP5 $(0.101 \mathrm{mmol} / \mathrm{L})$ treated $(\mathrm{A}-\mathrm{H})$. The white arrow points towards the cytoplasmic membrane $(\mathrm{CM})$ of the cell, which probably burst and release the entire cytoplasmic content to leave cell-wall relicts. CY, cytoplasm; CW, cell wall; DNA, deoxyribonucleic acid.

\section{Resistance Development Assay}

The antimicrobial resistance of PP5 against $P$. aeruginosa PAO1 was tested according to the method described by Yan, et al. ${ }^{7,8}$ In order to verify the development trend of PP5 compound resistance to the tested strains, we used polymyxin B (PM) as a positive control to analyze the development of drug resistance through continuous passages. We inoculated the single colony of the tested strain in the medium of liquid LB (containing 1\% Glc) for overnight culture. According to the growth conditions of the bacteria, the interval of one day was used as a passage. After harvesting the new bacteria, we measured the MIC value again; if the level of MIC value changed, the antibacterial concentration would be adjusted accordingly for the subsequent passage process. The resistance development of $P$. aeruginosa PAO1 to PP5 was observed after continuous passage for 18 generations. In addition, after 18 passages, we measured the MIC value on the 96-well plate and the colony number of the concentration on the solid TSA plate at the MIC value, as well as the change of the colony number compared with the control.

Table S1. MICs (mmol/L) of PM and PP5

\begin{tabular}{lcc}
\hline \hline Antibiotics & PM & PP5 \\
\cline { 2 - 3 } Times (d) & MIC & MIC \\
\hline
\end{tabular}




\begin{tabular}{|c|c|c|}
\hline 1 & 0.002 & 0.051 \\
\hline 2 & 0.002 & 0.051 \\
\hline 3 & 0.002 & 0.051 \\
\hline 4 & 0.002 & 0.025 \\
\hline 5 & 0.003 & 0.051 \\
\hline 6 & 0.003 & 0.051 \\
\hline 7 & 0.003 & 0.025 \\
\hline 8 & 0.006 & 0.025 \\
\hline 9 & 0.006 & 0.051 \\
\hline 10 & 0.025 & 0.051 \\
\hline 11 & 0.025 & 0.051 \\
\hline 12 & 0.050 & 0.101 \\
\hline 13 & 0.050 & 0.051 \\
\hline 14 & 0.050 & 0.051 \\
\hline 15 & 0.050 & 0.051 \\
\hline 16 & 0.050 & 0.051 \\
\hline 17 & 0.050 & 0.051 \\
\hline 18 & 0.050 & 0.051 \\
\hline
\end{tabular}




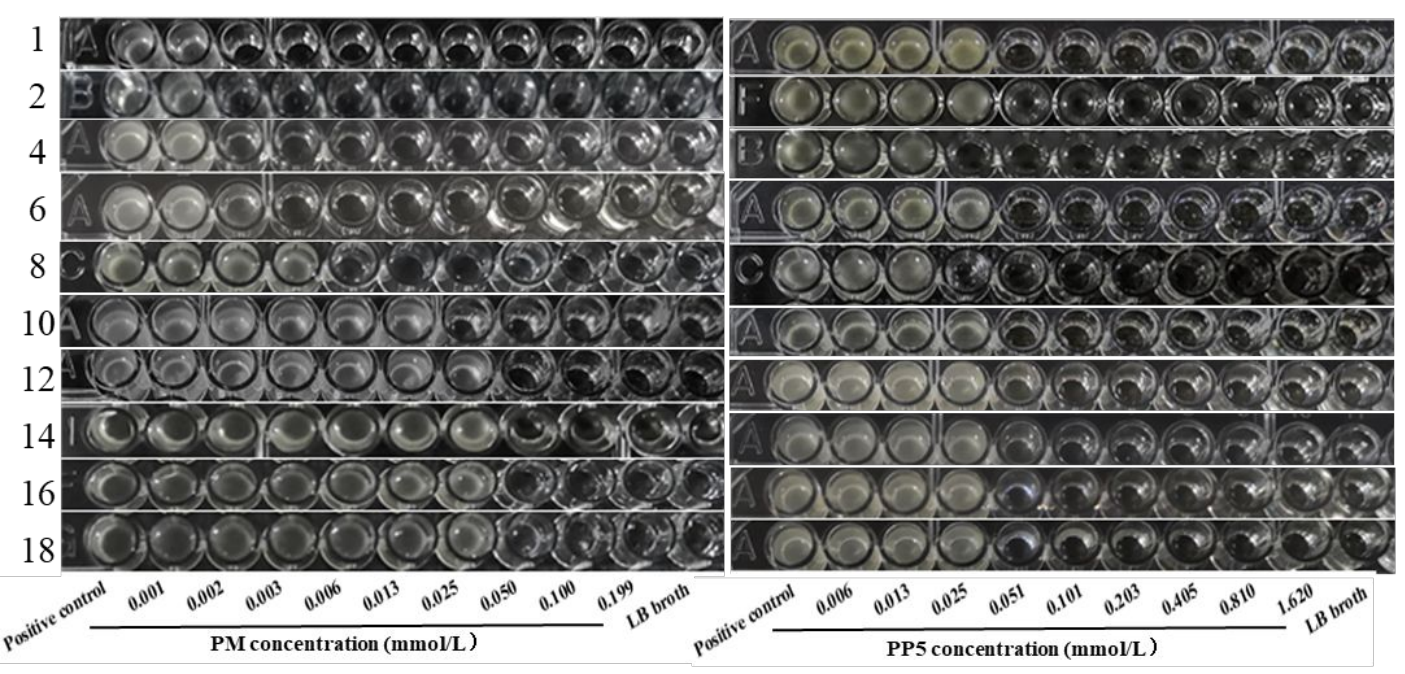

Figure S14. Analysis of resistance development of MIC values during successive passage process, which MICs of PM and PP5 against $P$. aeruginosa PAO1. The figure showed the MIC values after successive passages 1-18 days (from top to bottom).

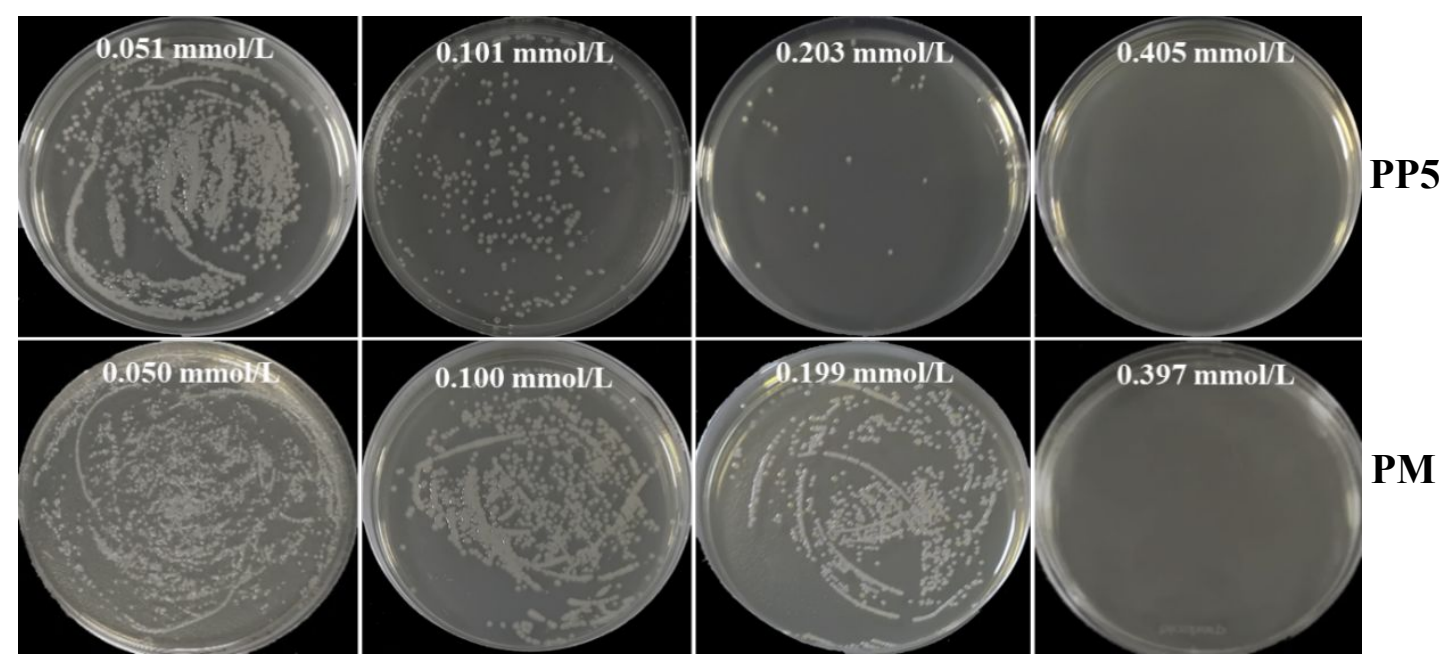

Figure S15. Images of $P$. aeruginosa PAO1 (eighteenth passages) colonies treated with

PP5 and PM on the TSA agar plates, respectively. All cells were incubated at $37{ }^{\circ} \mathrm{C}$ for $24 \mathrm{~h}$. 

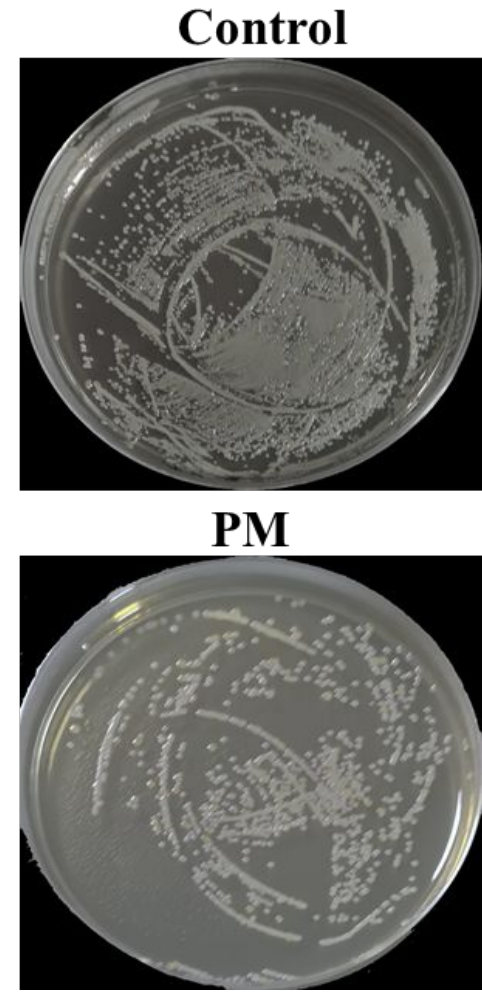

\section{PBS}

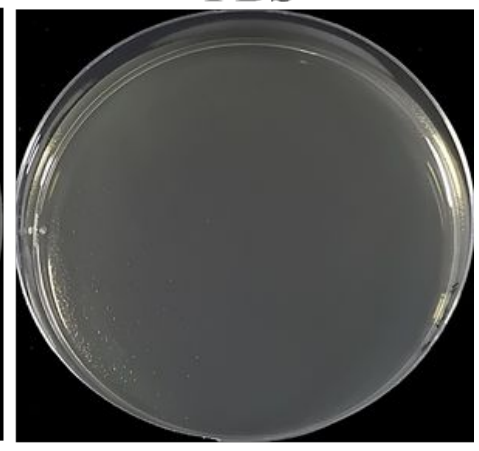

PP5

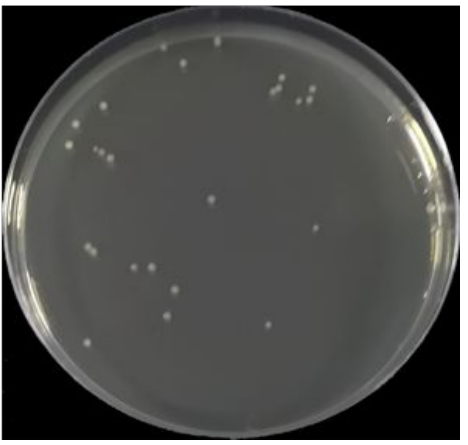

Figure S16. Images of $P$. aeruginosa PAO1 (eighteen repeatedly passages) colonies treated with PP5 (4 MIC), PM (4 MIC) on the TSA agar plates, respectively. All cells were subjected to $24 \mathrm{~h}$ of incubation at $37^{\circ} \mathrm{C}$.

\section{References}

(1) Ogoshi, T.; Akutsu, T.; Shimada, Y.; Yamagishi, T.-A. Redox-responsive host-guest system using redox-active pillar[5]arene containing one benzoquinone unit. Chemical Communications. 2016, 52, 6479-6481.

(2) Joseph, R.; Naugolny, A.; Feldman, M.; Herzog, I. M.; Fridman, M.; Cohen, Y. Cationic Pillararenes Potently Inhibit Biofilm Formation without Affecting Bacterial Growth and Viability.

Journal of the American Chemical Society. 2016, 138, 754-757. 
(3) Gao, L. Y.; Li, M. J.; Ehrmann, S.; Tu, Z. X.; Haag, R. Positively Charged Nanoaggregates Based on Zwitterionic Pillar[5]arene that Combat Planktonic Bacteria and Disrupt Biofilms. Angewandte Chemie-International Edition. 2019, 58, 3645-3649.

(4) Tan, H. L.; Peng, Z. X.; Li, Q. T.; Xu, X. F.; Guo, S. R.; Tang, T. T. The use of quaternised chitosan-loaded PMMA to inhibit biofilm formation and downregulate the virulence-associated gene expression of antibiotic-resistant staphylococcus. Biomaterials. 2012, 33, 365-377.

(5) Liu, Y. H.; Jiang, Y.; Zhu, J. L.; Huang, J. Y.; Zhang, H. J. Inhibition of bacterial adhesion and biofilm formation of sulfonated chitosan against Pseudomonas aeruginosa. Carbohydrate Polymers. 2019, 206, 412-419.

(6) Suo, B.; Yang, H.; Wang, Y. X.; Lv, H. P.; Li, Z., Xu, C.; Ai, Z. L. Comparative Proteomic and Morphological Change Analyses of Staphylococcus aureus During Resuscitation From Prolonged Freezing. Frontiers in Microbiology. 2018, 9, 866.

(7) Yan, S. Z.; Chen, S.; Gou, X. B.; Yang, J.; An, J. X.; Jin, X. Y.; Gao, H. Biodegradable Supramolecular Materials Based on Cationic Polyaspartamides and Pillar[5]arene for Targeting Gram-Positive Bacteria and Mitigating Antimicrobial Resistance. Advanced Functional Materials. 2019, 29, 11.

(8) Le, P. L.; Kunold, E.; Macsics, R.; Rox, K.; Jennings, M. C.; Ugur, I.; Sieber, S. A. Repurposing human kinase inhibitors to create an antibiotic active against drug-resistant Staphylococcus aureus, persisters and biofilms. Nature Chemistry. 2020, 12, 145-+. 